THE UNIVERSITY OF

WARWICK

\begin{tabular}{||l||}
\hline Mar $2016 \quad$ No.281 \\
Legislative Bargaining with Endogenous Rules \\
Jon X. Eguia and Kenneth A. Shepsle \\
\hline
\end{tabular}

WORKING PAPER SERIES

Centre for Competitive Advantage in the Global Economy

Department of Economics 


\title{
Legislative Bargaining with Endogenous Rules
}

\author{
Jon X. Eguia, Michigan State University and University of Bristol \\ Kenneth A. Shepsle, Harvard University
}

We study repeated legislative bargaining in an assembly that chooses its bargaining rules endogenously and whose members face an election after each legislative term. An agenda protocol or bargaining rule assigns to each legislator a probability of being recognized to make a policy proposal in the assembly. We predict that the agenda protocol chosen in equilibrium disproportionately favors more senior legislators, granting them greater opportunities to make policy proposals, and it generates an incumbency advantage to all legislators.

egislative rules affect legislative outcomes. But where do these rules come from? Legislators bargain over them. Once procedural protocols are in place, legislators bargain over policy. The chosen procedural rules thus have important consequences for bargained policy outcomes. We wish to understand how rules are chosen and their effect on policy.

The literature on legislative bargaining (Banks and Duggan 2000; Baron 1996; Baron and Ferejohn 1989; Binmore 1986; Merlo and Wilson 1995; Morelli 1999; among many others) typically assumes that bargaining occurs under fixed rules. But this isn't always so-rules are often chosen by the agents themselves before their actual policy bargaining begins. Each chamber of the US Congress, for example, is a "self-governing" group and, as instructed by Article I, Section 5, of the US Constitution ("each House may determine the Rules of its Proceedings"), establishes its own rules rather than accepting exogenous ones.

We build from two key premises: the set of bargaining legislators is determined by elections in each period, and legislators choose the institutional rules that govern their bargaining game. We thus present an electoral dynamic theory of endogenous institutions. Our main result is to characterize the stationary equilibrium that maximizes incumbents' utility.
The shadow of a future election looms large in the incumbents' choice of contemporaneous legislative rules. Incumbent legislators seek to be reelected, so they choose rules that help them secure this goal (Mayhew 1974). We identify the bargaining rule that helps them the most. This rule grants disproportionate proposal power to senior legislators, who use it to obtain more favorable policies and a greater share of resources for their constituencies. We demonstrate that this induces voters in every district to prefer reelecting their incumbent to electing a newly minted legislator. In addition to its relevance to the internal politics of the legislature and to electoral outcomes, seniority practices dramatically affect policypayoff inequality across districts as a consequence of distributive advantages enjoyed by those privileged in agenda rules. ${ }^{1}$

McKelvey and Riezman (1992) — hereafter MR92 - were the first to prove that the institution of a seniority rule can benefit each incumbent legislator in his or her pursuit of reelection. MR92 compare two rules: a default rule that treats all legislators equally in making policy proposals and an exogenous alternative rule that makes a binary distinction between legislators and favors all reelected legislators over those newly elected. MR92 find an equilibrium in which legislators prefer this alternative rule to the default.

MR92's seniority result hinges on a peculiar feature: their seniority rule, if approved, applies only to the first

Jon X. Eguia (corresponding author; eguia@msu.edu) is an associate professor of economics at Michigan State University and a Reader in economics at the University of Bristol. Kenneth A. Shepsle (kshepsle@iq.harvard.edu) is the George Markham Professor of Government at Harvard University.

The source of the data for figure 1 is the replication data set for Hall and Shepsle (2014), available in the JOP Dataverse (https://dataverse.harvard.edu /dataset.xhtml?persistentId = hdl:1902.1/21949). An online appendix with supplementary material is available at http://dx.doi.org/10.1086/682389.

1. Empirical evidence confirms that legislators who exercise more proposal power obtain more resources for their districts (Knight 2005), which helps them to be reelected more often (Levitt and Snyder 1997) and to obtain more votes in the next election (Loewen et al. 2014).

The Journal of Politics, volume 77, number 4. Published online August 11, 2015. http://dx.doi.org/10.1086/682389

(C) 2015 by the Southern Political Science Association. All rights reserved. 0022-3816/2015/7704-0014\$10.00

1076 
proposal to divide a surplus, with reversion to the default egalitarian rule for any subsequent proposal (required if the first is defeated). ${ }^{2}$ McKelvey and Riezman (1993)- -hereafter MR93 - show that if the seniority rule, once approved, is used throughout the legislative session, then "any equilibria will have the property that seniority has no benefits for legislators" (McKelvey and Riezman 1993, 288); that is, the main result of MR92 breaks down. McKelvey and Riezman (1992, 952) and MR93 regard this fragility of their seniority equilibrium "a rather paradoxical result."

We resolve this paradox by first presenting a theory of rules selection in which legislators can choose any rule, and then identifying the equilibrium rule that benefits legislators the most. We study a game with infinitely many periods. In each period, a first legislative stage (rules-selection stage) occurs in a "procedural state of nature" (Cox 2006) and determines the bargaining rules in operation at a second legislative stage (policy-determination stage). An election follows.

We depart from MR92 and MR93 by endogenizing the rules under consideration. Instead of restricting legislators to a binary choice between an exogenously given seniority rule and a default, in our theory legislators choose from an unconstrained menu of alternative agenda procedures, and seniority-based rules emerge endogenously. Our equilibrium rule is preferred not only to the equal treatment default rule but also to any other rule. We show that this rule discriminates on the basis of seniority, not on other factors, and it favors more senior legislators. This equilibrium seniority rule is not either of the two exogenous seniority rules studied in MR92 or MR93.

The substantive differences are important. In the MR92 and MR93 equilibria, expected payoffs are equal across legislators and districts. We show, in contrast, that legislators' preferred equilibrium rule makes them and their districts unequal, with expected utility increasing in seniority. Because expected payoffs for the constituency are increasing in its representative's seniority, and since a reelected incumbent would always be more senior than a newly elected challenger, constituents have an incentive to reelect their incumbents, even junior ones. Our equilibrium rule maximizes this incentive and, with it, the incumbents' expected payoff.

\section{RELATION TO THE BROADER LITERATURE}

Early papers by Banks and Gasmi (1987), Harrington (1990), Holcombe (1989), and Romer and Rosenthal (1978) (along with Baron and Ferejohn 1989) identify agenda power as a

2. A variation of MR92 by Muthoo and Shepsle (2014) also assumes that a seniority rule would be used-if approved - only for the first proposal. key determinant of equilibrium outcomes in majoritarian legislative bargaining, but they take the agenda institutions as given rather than chosen.

More recent contributions provide insights about specific features of agenda and voting institutions. Norman (2002) considers bargaining over finitely many periods. Breitmoser (2011), Cotton (2012), and Ali, Bernheim, and Fan (2014) consider variations of Baron and Ferejohn (1989) bargaining in which the identity of the policy proposer in future rounds is not entirely random. Yildirim $(2007,2010)$ assumes that each legislator's probability of recognition is proportional to the effort that the legislator invests in gaining agenda power. ${ }^{3}$ The literature on dynamic legislative bargaining with an endogenous status quo (Anesi and Siedmann, forthcoming; Baron and Bowen 2013; Bowen, Chen, and Eraslan 2014; Bowen and Zahran 2012; Dziuda and Loeper, forthcoming; Epple and Riordan 1987; Kalandrakis 2004; Nunnari 2012; Nunnari and Zapal 2013; or Penn 2009) recognizes that legislative bargaining is repeated anew in each legislative period and assumes that the period outcome in case of bargaining failure is equal to the previous period policy, but it continues to assume that the rules of the game are otherwise fixed. Jeon (2015) endogenizes the rules as well, assuming that each legislator's probability of recognition is equal to the legislator's policy allocation in the previous period. While these papers show that various agenda institutions can exaggerate or diminish the skew in expected payoffs, they provide no sense of whether such arrangements would ever have been chosen by the legislature in a "procedural state of nature."

Duggan and Kalandrakis (2012) allow committee members to choose procedural rules in each period as an extension to their dynamic model of legislative bargaining. They show that an equilibrium exists in this extended model, but they do not explore its properties beyond existence. The endogeneity of agenda institutions is central to a recent paper by Diermeier, Prato, and Vlaicu (2014). They consider a selfgoverning group that first selects the procedures by which it will conduct all its remaining business. They note two stylized facts: procedures grant asymmetric agenda advantage to some agents and are persistent, that is, not (often) revoked by a majority. They explain these facts in a one-dimensional

3. Other contributions that take the rules as fixed focus attention on voting rules that depend on the motion on the floor (Gersbach 2004) or on reconsideration of an approved policy (Diermeier and Fong 2011), or that allow weighted majority voting with unequal voting weights (Snyder, Ting, and Ansolabehere 2005). Montero (2007) introduces agents with inequality aversion, and Okada (2011) agents who differ both in their probabilities of recognition and in their time discount factors. The recent literature on divide-the-dollar legislative bargaining is vast; Eraslan and McLennan (2013) provide an extensive list of references. 
spatial model with Baron and Ferejohn (1989) bargaining and single-peaked legislator policy preferences. Their theory is static: at the end of one session of the assembly, the game ends. Since there is no future and no election, legislators need not take into account reelection pressures; and thus there is no scope to study the incentives to institute seniority rules.

Our dynamic electoral theory of institutions and legislative bargaining advances an understanding of the relationship between procedural choice and seniority, and their connection to an incumbency advantage. Moving beyond models in which the procedural options are limited and predetermined, our model allows the procedure itself to be endogenously determined. We identify an equilibrium rule in which the proposer and senior colleagues share proposal power and juniors are excluded, and show that this rule uniquely maximizes incumbents' utility as well as the incentive for a constituency to maintain its representative's place on the seniority ladder.

\section{THE MODEL}

Consider an infinite horizon dynamic game $\Gamma$ played by a fixed set $N$ of voters of odd size $n$, and a set of politicians who represent the voters in a legislative assembly. ${ }^{4}$ Assume there exist $n$ districts, with one representative voter in each district. An arbitrary period is denoted by $t$. Let $\Gamma_{t}$ be the period game played in period $t$. This period game is played by $2 n$ agents: the $n$ voters and $n$ politicians, each politician serving as the representative of a given district in period $t$. Representatives in any given period are strictly ordered by their seniority in the assembly, measured by the time since they first joined the assembly: let $\theta_{t}=\left(\theta_{t}^{1}, \ldots, \theta_{t}^{n}\right)$ be a state variable that denotes the seniority order in period $t$, where $\theta_{t}^{i}=k \in\{1,2, \ldots, n\}$ means that the representative from district $i$ is the $k$ th most senior representative in period $t$. The period $t$ game $\Gamma_{t}$ has one nonstrategic pre-stage and three stages:

\section{Stage o. Pre-stage: Assignment of seniority order}

At the beginning of each period $t>1$, we assign seniority ranks $\theta_{\mathrm{t}}$ as follows. ${ }^{5}$ Representatives who had first joined the assembly in any period $t^{\prime}<t$ and serve again in period $t$, preserve their relative position from period $t-1$, that is, for any pair of reelected representatives serving districts $i$ and $j, \theta_{t}^{i}<\theta_{t}^{j} \Leftrightarrow \theta_{t-1}^{i}<\theta_{t-1}^{j}$. Each reelected representative $j$

4. We initially consider politicians drawn from an infinite pool of homogeneous agents. We introduce heterogeneous politicians with idiosyncratic traits in an appendix.

5. Representatives in $t=1$ and their seniority ranking are given by an exogenous constitutional process that precedes the rest of the game. improves as many positions in the seniority order as the number of positions vacated by representatives with a more senior position than $j$ in period $t-1$ who do not serve in the assembly in period $t$. Any new politician who joins the assembly for the first time in period $t$ receives the last position $(n)$ in the seniority order; if there are multiple newly elected representatives, some exogenous (possibly random) rule assigns the last positions in the seniority ranking among them. ${ }^{6}$

\section{Stage 1. Rules-selection stage}

This stage contains three substages. We refer to them as "rounds." In the first round, Nature randomly selects a district to propose a rule (described below). For expositional simplicity, assume that each district is selected with equal probability (we relax this assumption and prove all the results with a more general probability distribution in an online appendix). Let $r(t)$ be the district selected.

In the second round, the representative from district $r(t)$ proposes an institutional arrangement $a_{t}$, which is a recognition rule indicating the probability that each representative is recognized to make a proposal at the policy-determination stage (see Stage 2). ${ }^{7}$ Formally, $a_{t}: N \rightarrow[0,1]$ is a function such that $\sum_{i=1}^{n} a_{t}(i)=1$ and $a_{t} \geq 0$, so that $a_{t}(i)$ denotes the probability that the representative from district $i$ is recognized to make a proposal at the policy-determination stage.

In the third round, each representative votes either in favor of recognition rule $a_{t}$, or against it. If a simple majority of representatives votes in favor, the outcome is recognition rule $a_{t} .{ }^{8}$ Otherwise, the reversion rule $\bar{a}$ prevails in which each representative is recognized with equal probability in the policy-determination stage: $\bar{a}(i)=1 / n$ for each district $i$. The legislature thus operates under "general parliamentary law" in which legislators are treated equally. Let $\hat{a}_{t} \in\left\{a_{t}, \bar{a}\right\}$ be the rule selected. ${ }^{9}$

6. This describes how real legislatures, such as the US House of Representatives, operate. Some measure of previous service weakly orders all legislators; ties are then broken by the application of second-order criteria (for example, prior service in one in a hierarchy of offices is used in the US House, e.g., governor, state senator, state representative, etc.); if these should fail to break all ties, randomization is employed (Kellermann and Shepsle 2009).

7. On the concept of proposal rights as a measure of political power in a democratic assembly, see Kalandrakis (2006).

8. Our results extend to supermajority acceptance rules (see the appendix).

9. Many legislatures in the real world conform to this abstract formulation-for instance, each time a new US House of Representatives convenes every two years, it is initially governed by "general parliamentary law," which means simple majority rule. Via general parliamentary law it elects a Speaker and passes a proposal for rules. If this proposal fails, parliamentary law prevails until a new proposal for rules is accepted; i.e., the House does not revert to the rules in place in the previous period. 
We consider two versions of game $\Gamma$. In $\Gamma^{\infty}$ if either $a_{t}$ or $\bar{a}$ is the selected rule at the rule-selection stage, it prevails in every round of policy bargaining in period $t$. In contrast, in game $\Gamma^{1}$ the selected rule applies only to the first round of policy bargaining in period $t$; if the policy proposal fails there, so that subsequent bargaining rounds are required, then recognition in any subsequent round defaults to $\bar{a} \cdot{ }^{10}$

Most of our results hold identically for both games, so we present them together for the general case $\Gamma \in\left\{\Gamma^{1}, \Gamma^{\infty}\right\}$; we specify one or the other game only when results differ.

\section{Stage 2. Policy-determination stage}

At this stage, representatives play the Baron and Ferejohn (1989) legislative bargaining game in which a surplus is divided. This stage has up to infinitely many rounds $(\rho)$. The probability that the representative from district $i$ is recognized to make a policy proposal in the first round of policy bargaining $(\rho=1)$ is $\hat{a}_{t}(i)$. A policy proposal is a partition of the surplus among the $n$ districts. Representatives vote it up or down by simple majority rule. If a proposal is accepted in round $\rho$, the stage ends. If not, the stage moves to round $\rho+1$ with probability $\pi \in(0,1)$ and, with complementary probability $1-\pi$, the stage ends in a bargaining failure that results in an allocation of zero to each district. ${ }^{11}$ If bargaining reaches round $\rho>1$, the probability that the representative from $i$ is recognized to make a policy proposal in round $\rho$ is $\hat{a}_{t}(i)$ if the game is $\Gamma=\Gamma^{\infty}$ (the endogenous rules apply to every round), and it is $1 / n$ if $\Gamma=\Gamma^{1}$ (the endogenous rules apply only to the first round).

We allow for, but do not require, exogenous turnover (attrition) among representatives. We assume that at the end of stage 2, with exogenous probability $\alpha \in[0,1]$, one randomly chosen representative ends her legislative career and exits the game due to exogenous reasons (e.g., death, elevation to high executive office, selection for a remunerative privatesector position, criminal conviction). Each representative thus faces probability $\alpha / n$ of exogenous exit. If a representative exits the game, the vacancy is filled and the departing incumbent is replaced with a provisional representative drawn from the infinite pool of identical politicians. ${ }^{12}$

10. In the section on extensions we consider a more general setup, in which the rules proposer can propose not just an allocation of agenda power, but a different game altogether for the policy stage.

11. This is analogous to assuming that there is discounting at the rate $\pi$ per round, so the total prize for each district is discounted by $\pi^{\rho-1}$ if the proposal is accepted in round $\rho$.

12. A replacement representative enters the assembly with the lowest seniority ranking, but, if elected at stage 3 , she has higher seniority in period $t+1$ than any newly drawn politician who first joins the assembly in $t+1$ after winning the period $t$ stage 3 election.

\section{Stage 3. Election stage}

At the last stage of each period, all representatives still in the game, that is, those who have not departed for exogenous reasons at stage 2 , enter an election to retain office. In each district the representative voter chooses whether to reelect her representative or to elect a challenger drawn from the pool of politicians. If the voter chooses the new politician, he or she enters the assembly at the lowest level of seniority. Legislators who lose the election exit the game.

At the end of the election stage, the period ends, each representative (reelected or not) who took part in the period's legislative bargaining keeps a fraction $\lambda$ of the prize obtained by her district, and the voter in the district obtains a fraction $1-\lambda$. The game advances to the next period, with discount $\delta \in(0,1)$, so that a period payoff of $x$ at period $t+k$ evaluated at period $t$ has a present value of $\delta^{k} x$.

The game $\Gamma$ consists of the infinite sequence of period games $\Gamma_{t}$. We assume that all agents maximize the present value of their expected stream of period payoffs.

For each period $t$, let $\tau \in\{1,2,3\}$ denote a stage within the period, let $\tau=0$ denote the pre-stage that sets the seniority order for the period, and let $\rho \in\{1,2,3, \ldots\}$ denote a round within a stage. A history $h(t, \tau, \rho)$ contains all the information about the actions played by Nature and all agents in all periods through $t-1$, in all stages of period $t$ through stage $\tau-1$, and in all rounds of stage $\tau$ in period $t$ through round $\rho-1$. Given $h(t, \tau, \rho)$, let $\left.h(t, \tau, \rho)\right|_{(t, 1,1)}$ denote the history of play from $(t, 1,1)$ to $(t, \tau, \rho)$, that is, the history of play within period $t$ up to stage $\tau$ and round $\rho$.

Let $\theta_{t}^{i}(h(t, 1,1))$ be the seniority of the representative from district $i$ in period $t$, as a function of the history of play up to the end of period $t-1$.

A behavioral (possibly mixed) strategy $s^{j}$ for an agent $j$ is a sequence of mappings, one for each information set in which player $j$ can be called upon to make a move. Each of these mappings is a function from the history of play at this information set to the set of probability distributions over feasible actions for agent $j$. The representative of district $r(t)$ chooses a probability distribution (a recognition rule); all representatives make a binary choice approving or rejecting this probability distribution; then representatives engage in the standard Baron and Ferejohn (1989) bargaining game according to the proposed recognition rule (if accepted) or the reversion rule (if rejected); finally, voters make a binary choice. All agents, at each information set, can condition their actions on all the information available in the full history of play leading to that information set. Let $s$ denote a strategy profile, which maps history of play to a probability distribution over actions at each information node in the game. 
We are interested in subgame perfect equilibria of the game $\Gamma$ that are stationary across periods, so that each period game $\Gamma_{t}$ is solved independently of the history of play in previous periods. We call this Stationarity I. That is, we seek equilibria made up of behavioral strategies that describe how to play each period game conditioning only on information available within the period game. This information includes the characteristics of the representatives serving in the current period, including their seniority, and their actions within the period, but it does not include any details of play in previous periods. Furthermore, we are interested in the equilibrium strategies of the policy-determination game that are stationary in the sense defined by Baron and Ferejohn (1989); without this additional stationarity, the solution to the game is indeterminate, since almost any outcome could then be sustained in equilibrium (see Baron and Ferejohn 1989). We call this Stationarity II.

Definition 1. A strategy profile $s$ satisfies Stationarity I if for any voter $i$, for any two politicians $j_{1}$ and $j_{2}$, for any period $t$, stage $\tau$ and round $\rho$, and for any two histories $h^{1}(t, \tau, \rho)$ and $h^{2}(t, \tau, \rho)$ such that for $k \in\{1$, 2) politician $j_{k}$ represents $i$ given history $h^{k}(t, \tau, \rho)$ and such that $\theta_{t}\left(h^{1}(t, 1,1)\right)=\theta_{t}\left(h^{2}(t, 1,1)\right)$ and $h^{1}(t$, $\tau, \rho)\left.\right|_{(t, 1,1)}=\left.h^{2}(t, \tau, \rho)\right|_{(t, 1,1)}$, it follows that $s^{j_{1}}\left(h^{1}(t, \tau\right.$, $\rho))=s^{j_{2}}\left(h^{2}(t, \tau, \rho)\right)$ for the politicians and $s^{i}\left(h^{1}(t, \tau\right.$, $\rho))=s^{i}\left(h^{2}(t, \tau, \rho)\right)$ for the voter. ${ }^{13}$

Given any representative $j$, a strategy $s^{j}$ satisfies Stationarity II if for any period $t$, any rounds $\rho$ and $\rho^{\prime}$ and any history $h\left(t, \tau, \max \left\{\rho, \rho^{\prime}\right\}\right), s^{j}(h(t, 2, \rho))=$ $s^{j}\left(h\left(t, 2, \rho^{\prime}\right)\right)$.

An equilibrium is stationary if every strategy profile satisfies Stationarity I and every representative's strategy satisfies Stationarity II.

The intuition of Stationarity I is that if two histories lead to the same seniority ranking at the beginning of the period, then in a stationary strategy an agent does not dwell on details of play in previous periods to decide how to play in the current period. Stationarity II is the standard stationarity in Baron and Ferejohn (1989) bargaining, adapted to the notation of our framework. It implies that looking only at the policy bargaining stage in a given period, given two

13. Because we allow for the identity of a district's representative to vary over time, stationarity of play by the representative from district $i$ requires symmetry across politicians from the same district: identical politicians representing the same district must play identical strategies. Our definition of Stationarity I assumes this symmetry. structurally equivalent subgames (two subgames with identical continuation extended trees), agents play the same strategies in the two subgames; that is, if probabilities of recognition do not vary, agents play the same way in the subgame that starts after round 1 of bargaining or after round $\rho>1$ of bargaining.

As in most voting games, there exist many implausible equilibria in which all representatives vote in favor of any proposal: since no representative is pivotal in this case, representatives are indifferent about the votes they cast. In a one-shot game, such equilibria are discarded assuming that agents never play weakly dominated strategies and always vote as if they were pivotal. The analogous argument for dynamic games is to refine the set of equilibria by requiring each voter to eliminate any strategy that is weakly dominated in a given voting stage game considered in isolation while treating the equilibrium strategies of all players as fixed for all future stages and periods. These are "stage undominated strategies" (Baron and Kalai 1993). Eliminating strategies that violate stage weak dominance is equivalent to requiring each agent to vote as if she were pivotal in every subgame in which she is involved (Duggan and Fey 2006). We use this equivalence to define the refinement.

Definition 2. An equilibrium strategy profile $s$ satisfies stage weak dominance if for any period $t$, any representative $j$, and any history $h(t, \tau, \rho)$ such that a (rule or policy) proposal $x$ is put to a vote, given $s$ representative $j$ votes for $x$ if the continuation value for $j$ of passing $x$ is strictly greater than the continuation value of not passing $x$, and votes against $x$ if the continuation value for $j$ of not passing $x$ is strictly greater than the continuation value of passing $x$.

Stage weak dominance merely rules out equilibria in which voters vote against their strict interest because their votes do not count. Our solution concept is subgame perfect, stationary, stage weakly undominated Nash equilibrium. We refer to these equilibria simply as "equilibria."

\section{MULTIPLICITY OF EQUILIBRIA}

Our games feature multiple equilibria. In the next section, we select the equilibrium that is most favorable for incumbent representatives. First we identify a larger class of equilibria.

Start by considering a one-period game, with just one rules stage and one policy stage. If the legislature uses the default rule $\bar{a}$ (equal probability of recognition for each legislator) at the policy stage, the expected payoff for each district (to be split in proportion $\lambda: 1-\lambda$ between the rep- 
resentative and her constituency) is $1 / n$. Therefore, in order for a different rule to be approved at the rules stage, this alternative rule must yield an expected payoff of at least $1 / n$ to at least a minimum winning coalition of districts. The rules proposer maximizes her own expected utility by proposing a rule that gives probability of recognition $1 / n$ to $(n-1) / 2$ representatives, and keeps the rest $((n+1) / 2 n)$ for herself, zeroing out the remaining $(n-1) / 2$ representatives. This rule is approved with the votes of the representatives who get probability of recognition $1 / n$, who, as a result, also get $1 / n$ of the surplus (in expectation) to share with their constituents.

We can construct an equilibrium of the infinite-horizon dynamic game in which this one-period equilibrium is played in each period. In order for all voters to have incentives to reelect their representatives, the equilibrium must be such that having a more senior representative is not detrimental to constituents; otherwise districts would replace their incumbent. It suffices that the probability that the representative from district $i$ is included in other representatives' minimal winning coalition at the rules stage is weakly increasing in the seniority of the representative from $i$ (holding fixed the relative seniority order of all other representatives). If so, voters do not want to replace their incumbent with a new politician who would become the most junior, and least powerful, representative.

Our first result may be stated as follows. For any recognition rule $a_{t}$ such that (i) $(n-1) / 2$ representatives obtain probability of recognition $1 / n$ and the rules proposer obtains $(n+1) / 2 n$, and (ii) the probability that a representative is among those who obtain positive probability of recognition is nondecreasing in seniority, then there is an equilibrium in which, in each period $t$, recognition rule $a_{t}$ is approved by the assembly and all incumbents running for reelection are reelected. Each representative selects a minimum winning coalition (in such a way that in the aggregate senior representatives are more likely to be selected) and offers $1 / n$ recognition probability to her coalition partners. Let $C^{i}\left(\theta_{t}\right) \subset N$ be the coalition of size $(n+1) / 2$ of districts including district $i$, chosen by the representative from $i$ as a function of the seniority order $\theta_{t}$. Let $\left|\left\{i \in N: j \in C^{i}\left(\theta_{t}\right)\right\}\right|$ be the number of districts that include district $j$ in their winning coalition. The following result holds whether endogenous rules apply for only one round $\left(\Gamma^{1}\right)$ or for every round $\left(\Gamma^{\infty}\right)$.

Proposition 1. For any profile of minimum winning coalitions $\left(C^{1}\left(\theta_{t}\right), \ldots, C^{n}\left(\theta_{t}\right)\right)$ such that $\mid\{i \in N: j \in$ $\left.C^{i}\left(\theta_{t}\right)\right\} \mid$ is nondecreasing in the seniority of the representative from $j$, there exists an equilibrium of game $\Gamma$ in which, in each period $t$ : (i) The rules proposer $r(t)$ proposes recognition rule $a_{t}$ that assigns probability of recognition $1 / n$ for any $l$ in $C^{r(t)}$ (except for $r(t)$ herself) and probability $(n+1) / 2 n$ for $r(t)$.

(ii) Recognition rule $a_{t}$ is approved by the assembly, and all incumbents running for reelection are reelected.

If the comparative static between seniority and proposal power for any district $j$ is such that, holding constant the relative position of all other districts in the seniority order, the representative from $j$ becomes more likely to be among those who receive proposal power as she becomes more senior, and this inequality is strict ( $j$ becomes strictly more likely) at some point in the seniority ranking, then each district has a strict incentive to reelect its incumbent representative, except the district with the most junior representative, which is indifferent.

Example 1. Suppose $\Gamma=\Gamma^{1}$, there are three districts, and there is no exogenous turnover $(\alpha=0) .{ }^{14}$ There is an equilibrium consistent with proposition 1 in which the rules proposer offers $2 / 3$ policy-proposal probability for herself and $1 / 3$ probability for the most senior among the other two representatives, and hence the probability of being recognized to be policy proposer is

$$
\begin{aligned}
& \frac{1}{3}\left(\frac{2}{3}\right)+\frac{2}{3}\left(\frac{1}{3}\right)=\frac{4}{9} \\
& \frac{1}{3}\left(\frac{2}{3}\right)+\frac{1}{3}\left(\frac{1}{3}\right)=\frac{3}{9}
\end{aligned}
$$

and

$$
\frac{1}{3}\left(\frac{2}{3}\right)=\frac{2}{9}
$$

respectively, for the most senior, second most senior, and junior representative. In the subsequent policydetermination game, the policy proposer gets $2 / 3$ of the cake and, in expectation, the other two legislators get $1 / 6$ (ex post one gets $1 / 3$, the other 0 ). Expected period payoffs are

$$
\frac{4}{9}\left(\frac{2}{3}\right)+\frac{5}{9}\left(\frac{1}{6}\right)=\frac{7}{18}
$$

for the most senior representative, $6 / 18$ for the second most senior, and $5 / 18$ for the junior. Everyone is

14. For the purpose of this and all other numerical calculations, we take the limit $\pi \rightarrow 1$, that is, the probability that bargaining ends exogenously before reaching an agreement is vanishingly small. 
reelected, the two seniors strictly, the junior just weakly in the sense that the voters of the district are indifferent between reelecting and replacing.

Other equilibria exist as well, including one in which representatives choose coalition partners randomly and are never reelected, and qualitatively different equilibria in which voters use more sophisticated reelection strategies, as in the following example.

Example 2. Suppose $\Gamma=\Gamma^{1}$, there are three districts, and there is no exogenous turnover $(\alpha=0)$. Suppose voters reelect their representative if (i) she is not the most junior or (ii) she is the rules proposer or (iii) she obtains probability of recognition exactly $1 / 9$; and they replace her if none of these three conditions hold. So the junior representative, when not the rules proposer, votes in favor of a rule that grants her exactly $1 / 9$ recognition probability. This makes her a cheaper coalition partner at the rules-selection stage. Thus, the sequence of stages plays out as follows:

- If a senior is recognized, she proposes 8/9 recognition probability for herself and $1 / 9$ for the junior. The junior and the rules proposer vote in favor of this rule, and it is approved.

- If the junior is recognized, she proposes $2 / 3 \mathrm{rec}$ ognition probability for herself, and $1 / 3$ for a randomly chosen senior. The chosen senior and the junior vote in favor of this rule, and it is approved.

- In the policy-determination game, the policy proposer proposes $2 / 3$ of the cake for herself and $1 / 2$ to one of the others.

The probability that either senior becomes the policy proposer is

$$
\frac{1}{3}\left(\frac{8}{9}\right)+\frac{1}{3}\left(\frac{1}{6}\right)=\frac{19}{54}
$$

for the junior it is

$$
\frac{1}{3}\left(\frac{2}{3}\right)+\frac{2}{3}\left(\frac{1}{9}\right)=\frac{16}{54}
$$

Expected period payoffs are

$$
\frac{19}{54}\left(\frac{2}{3}\right)+\frac{35}{54}\left(\frac{1}{6}\right)=\frac{37}{108}
$$

for each senior, and

$$
\frac{16}{54}\left(\frac{2}{3}\right)+\frac{38}{54}\left(\frac{1}{6}\right)=\frac{34}{108},
$$

and everyone is reelected.

Notice that for the junior representative, the equilibrium probability of recognition and the expected period payoff are higher in example 2 than in example $1 .^{15}$

\section{EQUILIBRIUM SELECTION}

Equilibria in which voters use sophisticated reelection rules, as in example 2, raise questions of equilibrium selection, since we do not find equilibria such as these very plausible in terms of the ability of a constituency either to commit to so exotic a voting strategy or to communicate this strategy to its representative even if it could commit. We select equilibria in which voters do not use such sophisticated rules. Instead they use reelection rules that condition only on the outcome of the policy-determination stage. In particular, a standard cutoff rule is used according to which a legislator is reelected if and only if she provides a period payoff at least as high as the cutoff (assumed fixed across periods). We stress that we require the equilibrium strategies to be robust against any strategies, including sophisticated ones that condition on all available information about the history of play.

Cutoff reelection strategies rule out unintuitive equilibria such as the one in example 2, but they still allow for a variety of equilibria, including both equilibria in which incumbents get reelected, as in proposition 1 , and those in which legislators serve for one term, choose rules that do not favor seniority, and are never reelected.

Incumbents have a common incentive to coordinate on equilibria in which incumbents are reelected along the equilibrium path. Hereafter we restrict attention to equilibria with reelection.

We make an additional technical restriction on equilibrium selection, which applies only to game $\Gamma^{1}$. At the policydetermination stage of any period of game $\Gamma^{1}$, the remainder of the stage after the first policy proposer is drawn is identical to the remainder of the Baron and Ferejohn (1989) bargaining game after the first policy proposer is drawn. An equilibrium is such that the policy proposer forms a coalition of minimal winning size by offering fraction $1 / n$ of the cake to exactly $(n-1) / 2$ legislators and keeping the rest for

15. We can replicate these examples in game $\Gamma^{\infty}$, but the exact payoffs change. 
herself. Conditional on not being the proposer in bargaining round $\rho$, each legislator must be chosen for inclusion in the round $\rho$ coalition with equal probability. In the standard, symmetric equilibrium of the Baron and Ferejohn (1989) game, the proposer randomizes over her coalition partners. We select equilibria in which, at the policy-determination stage in each period $t$, equilibrium play follows this standard, symmetric solution. ${ }^{16}$

Let $\mathcal{E}(\Gamma)$ be the set of equilibria that satisfy the following properties:

Property 1. Voters use cutoff reelection rules, and incumbents are reelected along the equilibrium path.

Property 2. If $\Gamma=\Gamma^{1}$, at the policy-determination stage of any period $t$, representatives play the symmetric solution to the Baron and Ferejohn (1989) game. ${ }^{17}$

We argue that among all equilibria in $\mathcal{E}(\Gamma)$, representatives have a common incentive to coordinate on those that maximize their aggregate expected utility. We show that the equilibrium in $\mathcal{E}(\Gamma)$ that maximizes incumbents' sum of utilities is the equilibrium that maximizes their incumbency advantage. ${ }^{18}$

By "incumbency advantage" we mean the present discounted value of the payoff obtained by a district if it keeps its incumbent in office minus the payoff for the district if it replaces its incumbent with a newly elected politician. Because both constituency period payoffs and representative period payoffs are proportional to the share of surplus secured in the equilibrium outcome (no moral hazard), the equilibrium that generates a greatest electoral incumbency advantage (and thus the sharpest incentives to reelect incumbents) is the same equilibrium that generates the most favorable policies for the incumbents. Incumbency advantage in our model is a valence that arises endogenously as a result of the institutional rules chosen in the assembly, and makes the incumbent more attractive than a potential challenger. ${ }^{19}$ Ashworth and Bueno de Mesquita (2008, 2009)

16. Alternatively, in asymmetric equilibria, different proposers choose different coalitions, but in such a correlated way that ex ante all agents are equally likely to be included in a coalition (for instance, with $n=3$, agent 1 may always choose agent 2, who always chooses agent 3 , who always chooses agent 1; see Baron and Ferejohn 1989, n. 16).

17. If $\Gamma=\Gamma^{\infty}$, property 2 imposes no restriction, so $\mathcal{E}\left(\Gamma^{\infty}\right)$ is the set of equilibria satisfying property 1 .

18. The set $\mathcal{E}(\Gamma)$ is not empty: for instance, the class of equilibria identified in proposition 1 belongs to $\mathcal{E}(\Gamma)$.

19. Valence characteristics are those on which there is a constituency consensus that the characteristic is desirable. A sampling of the literature on electoral competition with valence includes Ansolabehere and Snyder and Serra (2010) assume that politicians can engage in costly actions to increase their valence. We show that incumbents have a unique opportunity to increase their electoral valence at no cost by approving procedural rules that favor seniority.

More formally, let $E$ denote an equilibrium. For any period $t$ and any seniority vector $\theta_{t}$, let $\phi^{i, y}\left(\theta_{t}, E\right)$ be the present value of the expected stream of future payoffs evaluated at period $t$ for a district $i$ that reelects its incumbent, given that continuation play will be according to equilibrium $E$. This present value may depend on the seniority order, but by stationarity, it does not depend on period $t$. Let $\phi^{i, n}\left(\theta_{t}, E\right)$ be the same present value if the district does not reelect its incumbent. Then the incumbency advantage of legislator $i$ is $\phi^{i, y}\left(\theta_{t}, E\right)-\phi^{i, n}\left(\theta_{t}, E\right)$, that is, the value of reelecting the incumbent from district $i$ given her seniority minus the value of replacing the incumbent with a challenger.

The average incumbency advantage at period $t$ given seniority vector $\theta_{t}$ is:

$$
\sum_{i=1}^{n} \frac{\phi^{i, y}\left(\theta_{t}, E\right)-\phi^{i, n}\left(\theta_{t}, E\right)}{n} .
$$

Definition 3. We say that equilibrium $E \in \mathcal{E}(\Gamma) \max$ imizes incumbency advantage within $\mathcal{E}(\Gamma)$ if

$$
E \in \arg \max _{\{E \in \mathcal{E}(\Gamma)\}} \sum_{i=1}^{n} \frac{\phi^{i, y}\left(\theta_{t}, E\right)-\phi^{i, n}\left(\theta_{t}, E\right)}{n}
$$

for any seniority vector $\theta_{t}$; that is, if $E$ maximizes the average difference in the present value of reelecting an incumbent minus the present value of replacing the incumbent.

Let $V^{i}\left(\theta_{t}, E\right)$ be the present value at $t$ of the expected stream of future payoffs that accrue to the current incumbent of district $i$, given equilibrium $E$. This present value, again by stationarity, does not depend on period $t$.

Claim 1. Assume there is attrition $(\alpha>0)$. Equilibrium $E \in \mathcal{E}(\Gamma)$ maximizes incumbency advantage within $\mathcal{E}(\Gamma)$ if and only if it maximizes the sum of incumbents' utilities $\sum_{i=1}^{n} V^{i}\left(\theta_{t}, E\right)$ for any seniority vector $\theta_{t}{ }^{20}$

It could be argued that since each incumbent prefers the equilibrium that maximizes her own utility and incumbency

(2000), Aragones and Palfrey (2004), Enelow and Hinich (1982), Groseclose (2001), and Stone and Simas (2010).

20. If there is no attrition, an equilibrium that maximizes incumbency advantage also maximizes incumbents' sum of utilities, but not uniquely. 
advantage, incumbents face a coordination problem. However, note first that incumbents cannot affect their own incumbency advantage; rather, by choosing coalition partners at the rules stage, the representative from $i$ can affect the utility and incumbency advantage of any other representative, but not her own. It is the other representatives who determine $i$ 's incumbency advantage by their own choices when they are the rules proposer. This mutual dependency induces coordination on the mutually beneficial rule that maximizes aggregate incumbents' utility and incumbency advantage. Furthermore, the equilibrium that maximizes total or average incumbents' utility and incumbency advantage is also the equilibrium that maximizes individual utility and incumbency advantage for a majority of incumbents, including the incumbent with median seniority. We thus find that this incumbent-preferred equilibrium is doubly focal, even if politicians have no proclivity toward collusion.

The institutional arrangement that favors incumbents most is the one that keeps the stream of future payoffs for the constituency that replaces its representative very low for as many periods as possible. This is achieved by concentrating all the probability of recognition on senior representatives. In particular, by zeroing out the probability of recognition of all representatives with less than median seniority, a constituency that replaces its incumbent will have to wait the maximal amount of time, given exogenous turnover, before their newly minted representative rises sufficiently on the seniority ladder to qualify for positive probability of recognition and a greater than minimal expectation of payments.

Our main result identifies this incumbent-preferred equilibrium, which maximizes their aggregate utilities and incumbency advantage. The result applies to both games $\Gamma^{1}$ and $\Gamma^{\infty}$. Let $N^{-r(t)}=N /\{r(t)\}$ denote the set of districts excluding the district of the rules proposer $r(t)$.

Proposition 2. If the exogenous probability of attrition $\alpha$ is strictly positive, there is an equilibrium that uniquely maximizes incumbency advantage in $\mathcal{E}(\Gamma)$. In this equilibrium, in each period $t$, the recognition rule $a_{t}^{*}$ assigns probability of recognition $a_{t}^{*}(i)=1 / n$ to the $(n-1) / 2$ most senior representatives in $N^{-\mathrm{r}(t)}$ and leaves the remaining probability $a_{t}^{*}(r(t))=(n+1) / 2 n$ for the rules proposer. If $\alpha=0$, this equilibrium maximizes incumbency advantage, but not uniquely.

Incumbency advantage is maximized by forming a coalition of minimal winning size at the rule-proposal stage with the rules proposer and the most senior representatives, and distributing all the probability of recognition within this senior coalition. Under the assumption that the prob- ability to be recognized to make a rules proposal is uniform across all representatives, the present value of the stream of payoffs for each district in this equilibrium is strictly increasing in seniority for districts with a representative with less than median seniority, and constant at the highest value for any representative with more than median seniority (see the next section for evidence).

We illustrate proposition 2, providing numerical details of the equilibrium in an example with 15 districts, $\alpha=1$ (attrition of one legislator per period) and $\delta \rightarrow 1$ (patient agents).

Table 1 quantifies the incumbency advantage in game $\Gamma^{1}$ (endogenous recognition rules apply to only to the first round of bargaining). The first and second columns present the seniority of each district's representative and the probability of being recognized to make the first policy proposal. The third, fourth, and fifth columns detail the expected period payoff for a district, the total expected future multiperiod payoff for the district while represented by the current representative, and the relative size of the incumbency advantage as a fraction of the payoffs obtained by the least senior representative.

In this example, a representative with seniority rank 1 through 7 obtains probability of recognition $8 / 15$ if she is the rules proposer (which occurs with probability $1 / 15$ ), and obtains probability of recognition $1 / 15$ otherwise. Hence, her expected probability of recognition is $8 / 15(1 / 15)+$ $1 / 15(14 / 15)=0.098$. In game $\Gamma^{\infty}$, period payoffs are lower for legislators with less than median seniority and higher for those with more than median seniority, and the incumbency advantage is twice as large for any seniority rank.

Table 1. Recognition Probabilities, Payoffs, and Incumbency Advantage in Game $\Gamma^{1}$

\begin{tabular}{lcccc}
\hline $\begin{array}{l}\text { Seniority } \\
\text { Rank }\end{array}$ & Pr[Recognition] & $\begin{array}{c}\text { Period } \\
\text { Payoff }\end{array}$ & $\begin{array}{c}\text { Total } \\
\text { Payoff }\end{array}$ & $\begin{array}{c}\text { Incumbency } \\
\text { Advantage } \\
(\%)\end{array}$ \\
\hline & & & & \\
$1-7$ & .098 & .082 & 1.233 & 23 \\
8 & .067 & .067 & 1.204 & 20 \\
9 & .036 & .051 & 1.156 & 16 \\
10 & .036 & .051 & 1.117 & 12 \\
11 & .036 & .051 & 1.085 & 9 \\
12 & .036 & .051 & 1.058 & 6 \\
13 & .036 & .051 & 1.036 & 4 \\
14 & .036 & .051 & 1.017 & 2 \\
15 & .036 & .051 & 1 & 0 \\
\hline
\end{tabular}




\section{GENERALIZATIONS AND EXTENSIONS}

We consider several generalizations: First we introduce a continuum of voters and probabilistic voting in each district; and second, we allow the rules proposer to propose any bargaining game with any timing and protocol for the policy determination stage. Due to space constraints we relegate to the appendix other extensions such as requiring a supermajority vote to approve any rule change; letting seniority be defined as a partial order based only on the number of terms in office, or considering politicians who are endowed with idiosyncratic traits.

\section{A continuum of voters}

Assume that in each district there is a continuum of voters with idiosyncratic tastes for or against individual politicians. Formally, assume that each voter $v$ in district $i$ experiences an idiosyncratic utility shock $\omega_{v, i, j}$ every period that $j$ represents district $i$, where each $\omega_{v, i, j}$ is independently drawn from a continuous, symmetric distribution with mean and median at 0 . In each election, the preference of voter $v$ with $\omega_{v, i, j}=0$ represents the majority preference of the district. All our other results take this voter $v$ as the representative agent.

With multiple voters incumbent $j$ wins the votes of every voter $v$ with $\omega_{v, i, j}>-\left(\phi_{t}^{i, y}(E)-\phi_{t}^{i, n}(E)\right)$. It follows that the margin of victory for incumbent $j$ is strictly increasing in $j$ 's incumbency advantage. Since as noted above incumbency advantage is itself strictly increasing in seniority up to median seniority and then flat, an empirical implication follows: the margin of victory for representatives is strictly increasing in seniority for junior legislators up to those with median seniority, and then it flattens out.

We provide some descriptive evidence which suggests that this prediction is consistent with the empirical pattern in data from the US House of Representatives over a 60year period (fig. 1). On the horizontal axis is the number of terms served and on the vertical axis is the mean incumbent plurality (based on the top two candidates) in percentage

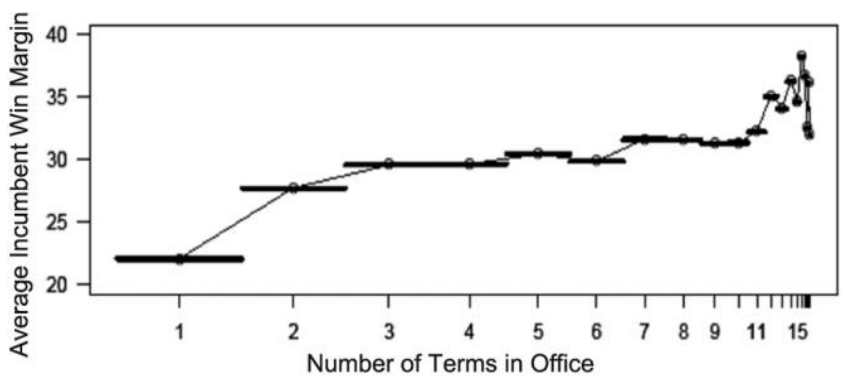

Figure 1. Seniority and incumbent performance, US House 1948-2008. Margin of victory as a function of number of terms in office. points. Thus, those with one previous term of service averaged a $22 \%$ plurality, that is, a $61 \%-39 \%$ victory. The width of each thick horizontal line is proportional to the number of Representatives with the given number of terms of office. As displayed, plurality rises with service on average until about the third term and is flatter thereafter. Since the average median length of service over the 60 -year period is 3.84 terms, the results conform to our conjecture. ${ }^{21}$

\section{A more general class of bargaining rules}

Let $\Gamma^{v a r}$ be a game that expands the class of feasible institutional arrangements by allowing the probabilities of recognition to vary over different rounds of policy bargaining. Assume that in game $\Gamma^{v a r}$ the rules proposer $r(t)$ can offer a rule that specifies a distinct vector of recognition probabilities for each round. Formally, the institutional arrangement in this extension is a sequence $\left\{a_{t, \rho}\right\}_{\rho}^{\infty}=1$, where for each round of policy bargaining $\rho, a_{t, \rho}: N \rightarrow[0,1]$ is a function such that $\sum_{i=1}^{n} a_{t, \rho}(i)=1$ and $a_{t, \rho}(i) \geq 0$ for each $i$, and $a_{t, \rho}(i)$ is the probability of recognition for the representative from $i$ in round $\rho$, subject to reaching this round of policy bargaining. This is a generalization of $\Gamma^{\infty}$ where $a_{t, \rho}(i)=a_{t}(i)$ for all $\rho$.

We find that the equilibrium that maximizes incumbency advantage in game $\Gamma^{\infty}$, in which the institutional rule assigns recognition probability $1 / n$ to the $(n-1) / 2$ most seniors other than $r(t)$ and all the rest of the recognition probability to the rules proposer $r(t)$ in every round of policy bargaining (proposition 2), also maximizes incumbents' aggregate utility incumbency advantage in the game $\Gamma^{\text {var }}$ with the expanded collection of feasible rules. The freedom to choose a rule that varies probabilities of recognition across rounds does not yield additional gains to incumbents: any advantage that can be gained with rules in which probabilities vary across rounds can also be attained with the simpler rule, constant over rounds, identified in proposition 2.

In fact, a stronger result holds. We can expand the collection of feasible institutional arrangements, allowing the rules proposer to introduce rules that assign unequal voting weights to different legislators or that change the timing of moves or the structure of the game. Most generally, we can allow the rules proposer to propose any stage game, finite or infinite, with discrete or continuous payoffs, static or dynamic, to be played at the policy stage, as long as the end result of this game is the allocation of a unit of wealth among players. Formally, let $\mathcal{G}$ be the set of all $n$-player games with

21. Note that the data for more than 10 terms is noisy because of very small numbers. A systematic statistical analysis, arriving at conclusions similar to ours, is found in Gelman and King (1990). 
nonnegative payoffs that add up to no more than one. Let $\Gamma^{\mathcal{G}}$ be the game in which at the rules stage, the rule proposer $r(t)$ is free to propose any game $G \in \mathcal{G}$, and if the proposal obtains a majority of votes in favor, then at the policy bargaining stage, game $G$ is played (if the proposal is defeated, the policy stage consists of playing the standard BaronFerejohn bargaining game). Among this maximally general class of institutional rules, playing the Baron-Ferejohn bargaining game with constant probabilities of recognition over every round as stated in proposition $2(1 / n$ for a minimal winning majority of seniors and the rest for the rules proposer) maximizes incumbency advantage and incumbents' utility.

Proposition 3. The equilibrium that uniquely maximizes incumbency advantage in $\Gamma^{\infty}$ identified in proposition 2 maximizes incumbency advantage in game $\Gamma^{\mathcal{G}}$.

Incumbents do not obtain any further gain from having any rule outside those we allow in game $\Gamma^{\infty}$ at their disposal.

\section{DISCUSSION}

Formal research on the origin of institutional rules that favor seniority in legislatures begins with the seminal paper, McKelvey and Riezman (1992). They establish that legislators prefer a legislative rule that gives agenda recognition advantage to all legislators who have been reelected at least once to one that treats all legislators equally.

We relax a number of artificial constraints in the modeling choices of MR92 and MR93, which allows us to obtain more realistic results, implications, and substantive insights. We discuss in turn the modeling choices and their implications.

\section{Modeling generalizations and improvements}

(i) Endogenous versus exogenous rules choice set. In MR92, the alternative rule put to a vote against the default of equal recognition is exogenously given, and it specifies that agenda power is shared equally among legislators who have been reelected at least once. In our theory, the alternative rule put to a vote is endogenous, drawn by a rules proposer from a large set that contains any vector of recognition probabilities or, in a generalization, any bargaining protocol (proposition 3). Among all rules, one conditioned on legislator seniority alone emerges as an equilibrium feature, not as a result of a forced choice. (ii) Endogenous versus exogenous assembly membership. Membership in MR92 legislatures is by assumption fixed over the infinite time horizon. In our theory, legislators exit the assembly if they lose an election or if they suffer an exogenous shock (such as death); hence, there is churning in assembly membership, a more realistic description.

(iii) Ordinal versus binary seniority. MR92 (and Muthoo and Shepsle 2014) assume that seniority is binary: a legislator either has seniority or does not. However, in reality, seniority consists of a strict ranking of legislators from most to least senior. We develop our results under an ordinal notion of seniority.

(iv) Heterogeneous versus identical politicians. In the appendix, we allow politicians to have idiosyncratic traits, and we expand the set of feasible legislative rules to include rules that condition on these traits. Nevertheless, we demonstrate that the rule that emerges in equilibrium continues to be a rule that conditions exclusively on seniority, and not on any other traits.

\section{Theoretical and substantive implications}

(i) Existence of a seniority equilibrium. MR92's seniority result holds only if the unequal recognition rule applies only to the first round of bargaining (as in game $\Gamma^{1}$ ). "When seniority is used throughout the session, there is no equilibrium in which seniority has benefit to legislators" (McKelvey and Riezman 1992, 958) and paraphrased in McKelvey and Riezman $(1993,288)$. We fully overturn this negative result: in the game in which the chosen rule holds for all rounds $\left(\Gamma^{\infty}\right)$, there is an equilibrium in which seniority benefits legislators. It's just that the equilibria that benefit seniors feature different rules than the one rule studied by MR92.

Leaving aside the case in which MR92 do not obtain a seniority result, we next compare the implication of our findings for the case in which they do.

(ii) Equilibrium predictions. In MR92's equilibrium, the agenda rule is such that along the equilibrium path all legislators share agenda power equally. However, we find that MR92's rule is not chosen in equilibrium once other rules are available. In the more general setting we study, a "seniority equilibrium" exists, but it features a rule that differs from the only alternative rule considered by 
MR92, by assigning positive recognition probability only to the selected rules proposer and his or her $(n-1) / 2$ most senior colleagues. This seniority equilibrium is the one preferred by incumbents, maximizing their aggregate utility and the incentives of constituents to reelect incumbents.

(iii) Inequality across districts. MR92's equilibrium predicts perfect equality in expected payoffs for every district in every period. In sharp contrast, our equilibrium predicts very unequal expected payoffs across districts. The legislators with more than median seniority obtain a much larger share of agenda power and a much greater expected payoff than legislators with less than median seniority. Nevertheless, even the junior legislators are reelected in equilibrium since their constituents are eager to preserve their incumbent's place in the seniority queue.

(iv) Persistence and cumulativeness of inequality. Since reelected incumbents maintain their seniority across periods, districts with a more senior legislator remain privileged as long as their representatives remain in the assembly, and therefore the inequality in outcomes cumulates over the lifespan of a political career. Exogenous shocks to the composition of the assembly $(\alpha>0)$ generate churning, and every district is eventually represented by a junior legislator. Hence, while privilege is persistent, it is not everlasting.

(v) Illusiveness of constitutional equality. Most representative democracies are founded on the notion of equality across units of representation. The units of representation are citizens (as in the US House of Representatives) or political units such as states, provinces, or Länder (as in the US Senate). In either case, the principles of electing a fixed number of representatives per unit of representation, and of assigning one vote to each representative, jointly guarantee equal voting power to each unit of representation.

Our results emphatically deny the sufficiency of voting equality for constitutional equality. Reelection-oriented legislators craft institutional arrangements that, while preserving voting equality, generate political and economic inequality among units of representation, favoring those represented by legislators with greater seniority. These institutional rules violate the democratic Principle of Effective Participation, defined by Dahl as follows: "Throughout the process of making binding deci- sions, citizens ought to have an adequate opportunity, and an equal opportunity, for expressing their preferences as to the final outcome. They must [also] have adequate and equal opportunities for placing questions on the agenda" (Dahl 1989, 109). ${ }^{22}$ Constitutional equality requires both equal voting power and equal “voice.” Seniority rules deny this very equality in citizen voice by institutionalizing inequality in the voices of their representatives through nonuniform access to the agenda.

\section{ACKNOWLEDGMENTS}

Abinhay Muthoo collaborated with us at the inception of this project, and we remain grateful to him. We have also benefited from contributions of ideas and suggestions by Vincent Anesi, Ken Binmore, Renee Bowen, John Duggan, Hülya Eraslan, Sean Gailmard, Andrew Hall, Tasos Kalandrakis, John Matsusaka, Salvatore Nunnari, Santiago Oliveros, Ryan Pevnick, Carlo Prato, Melissa Schwartzberg, Jim Snyder, Razvan Vlaicu, Lisa Windsteiger, two anonymous reviewers, and audiences at Rochester, University of Southern California, Washington University, Malaga, Nottingham, Columbia, Berkeley, Harvard, Bristol, Warwick, the London School of Economics, the Canadian Institute for Advanced Research, and the 2014 SITE workshop on dynamic collective decision making.

\section{REFERENCES}

Ali, Nageeb, B. Douglas Bernheim, and Xiaochen Fan. 2014. "Predictability and Power in Legislative Bargaining." NBER Working Paper 20011, National Bureau of Economic Research, Cambridge, MA.

Anesi, Vincent, and Daniel Seidmann. Forthcoming. "Bargaining in Standing Committees with an Endogenous Default." Review of Economic Studies.

Ansolabehere, Stephen, and James M. Snyder. 2000. "Valence Politics and Equilibrium in Spatial Election Models." Public Choice 103:327-36.

Aragones, Enriqueta, and Thomas R. Palfrey. 2004. "The Effect of Candidate Quality on Electoral Equilibrium.” American Political Science Review 98:77-90.

Ashworth, Scott, and Ethan Bueno de Mesquita. 2008. "Electoral Selection, Strategic Challenger Entry, and the Incumbency Advantage." Journal of Politics 70 (4): 1006-25.

Ashworth, Scott, and Ethan Bueno de Mesquita. 2009. "Elections with Platform and Valence Competition." Games and Economic Behavior 67 (1): 191-216.

22. In its decision on Reynolds $v$. Sims (377 US 533 (1964)), the US Supreme Court echoes this principle and insists on the right to "full and effective participation by all citizens in state government" which, in turn, "requires ... that each citizen have an equally effective voice in the election of members of his state legislature." Extending the argument from the election to the legislature, we note that such equality of participation at the election is illusory if subsequently some of the elected legislators have no effective voice in the legislature. 
1088 / Legislative Bargaining with Endogenous Rules Jon X. Eguia and Kenneth A. Shepsle

Banks, Jeffrey, and John Duggan. 2000. “A Bargaining Model of Collective Choice." American Political Science Review 94:73-88.

Banks, Jeffrey, and F. Gasmi. 1987. "Endogenous Agenda Formation in Three-Person Committees." Social Choice and Welfare 4:133-52.

Baron, David. 1996. "A Dynamic Theory of Collective Goods Programs.” American Political Science Review 90 (2): 316-30.

Baron, David, and T. Renee Bowen. 2013. "Dynamic Coalitions." Stanford Graduate School of Business Research Paper 2128, Stanford University.

Baron, David, and John Ferejohn. 1989. "Bargaining in Legislatures." American Political Science Review 83:1181-1206.

Baron, David, and Ehud Kalai. 1993. "The Simplest Equilibrium of a MajorityRule Division Game.” Journal of Economic Theory 61 (2): 290-301.

Binmore, Kenneth G. 1986. "Bargaining and Coalitions." In A. E. Roth, ed., Game-Theoretic Models of Bargaining. New York: Cambridge University Press, 269-304.

Bowen, T. Renee, Ying Chen, and Hülya Eraslan. 2014. "Mandatory versus Discretionary Spending: The Status Quo Effect.” American Economic Review 104 (10): 2941-74.

Bowen, T. Renee, and Zaki Zahran. 2012. "On Dynamic Compromise.” Games and Economic Behavior 76 (2): 391-419.

Breitmoser, Yves. 2011. "Parliamentary Bargaining with Priority Recognition for Committee Members.” Social Choice and Welfare 37 (1): 149-69.

Cotton, Christopher. 2012. "Dynamic Legislative Bargaining with Endogenous Agenda Setting." Working Paper, Department of Economics, University of Miami.

Cox, Gary W. 2006. "The Organization of Democratic Legislatures.” In Barry R. Weingast and Donald A. Wittman, eds., The Oxford Handbook of Political Economy. New York: Oxford University Press, 141-62.

Dahl, Robert A. 1989. Democracy and Its Critics. New Haven, CT: Yale University Press.

Diermeier, Daniel, and Pohan Fong. 2011. "Legislative Bargaining with Reconsideration.” Quarterly Journal of Economics 126:947-85.

Diermeier, Daniel, Carlo Prato, and Razvan Vlaicu. 2014. "Procedural Choice in Majoritarian Organizations." American Journal of Political Science, forthcoming.

Duggan, John, and Mark Fey. 2006. "Repeated Downsian Electoral Competition.” International Journal of Game Theory 35 (1): 39-69.

Duggan, John, and Tasos Kalandrakis. 2012. "Dynamic Legislative Policy Making." Journal of Economic Theory 147:1653-88.

Dziuda, Wioletta, and Antoine Loeper. Forthcoming. "Dynamic Collective Choice with Endogenous Status Quo.” Journal of Political Economy.

Enelow, James M., and Melvin J. Hinich. 1982. "Nonspatial Candidate Characteristics and Electoral Competition.” Journal of Politics 44:115-30.

Epple, Dennis, and Michael H. Riordan. 1987. "Cooperation and Punishment under Repeated Majority Voting.” Public Choice 55 (1-2): 41-73.

Eraslan, Hülya, and Andrew McLennan. 2013. "Uniqueness of Stationary Equilibrium Payoffs in Coalitional Bargaining.” Journal of Economic Theory 148:2195-2222.

Gelman, Andrew, and Gary King. 1990. "Estimating Incumbency Advantage without Bias.” American Journal of Political Science 34:1142-68.

Gersbach, Hans. 2004. "Dividing Resources by Flexible Majority Rules." Social Choice and Welfare 23:295-308.

Groseclose, Tim. 2001. "A Model of Candidate Location When One Candidate Has a Valence Advantage.” American Journal of Political Science 45:862-86.

Hall, Andrew B., and Kenneth A. Shepsle. 2014. "The Changing Value of Seniority in the U.S. House: Conditional Party Government Revised." Journal of Politics 76 (1): 96-113.

Harrington, Joseph E. 1990. "The Power of the Proposal Maker in a Model of Endogenous Agenda Formation.” Public Choice 64:1-20.

Holcombe, Randall. 1989. "A Note on Seniority and Political Competition.” Public Choice 61:285-88.
Jeon, Jee Seon. 2015. "The Emergence and Persistence of Oligarchy: A Dynamic Model of Endogenous Political Power." Unpublished manuscript.

Kalandrakis, Tasos. 2004. "A Three Player Majoritarian Bargaining Game.” Journal of Economic Theory 116 (2): 294-322.

Kalandrakis, Tasos. 2006. "Proposal Rights and Political Power." American Journal of Political Science 50:441-48.

Kellermann, Michael, and Kenneth A. Shepsle. 2009. "Congressional Careers, Committee Assignments, and Seniority Randomization in the US House of Representatives." Quarterly Journal of Political Science 4:87-101.

Knight, Brian. 2005. "Estimating the Value of Proposal Power." American Economic Review 95 (5): 1639-52.

Levitt, Steven D., and James M. Snyder. 1997. "The Impact of Federal Spending on House Election Outcomes." Journal of Political Economy 105 (1): 30-53.

Loewen, Peter J., Royce Koop, Jaime Settle, and James H. Fowler. 2014. “A Natural Experiment in Proposal Power and Electoral Success.” American Journal of Political Science 58 (1): 189-96.

Mayhew, David R. 1974. Congress: The Electoral Connection. New Haven, CT: Yale University Press.

McKelvey, Richard D., and Raymond Riezman. 1992. "Seniority in Legislatures." American Political Science Review 86 (4): 951-65.

McKelvey, Richard D., and Raymond Riezman. 1993. "Initial versus Continuing Proposal Power in Legislative Seniority Systems." In W. Barnett, M. Hinich, and N. Schofield, eds., Political Economy: Institutions, Competition and Representation. Cambridge: Cambridge University Press.

Merlo, Antonio, and Charles Wilson. 1995. "A Stochastic Model of Sequential Bargaining with Complete Information.” Econometrica 63 (2): 371-99.

Montero, Maria. 2007. "Inequality Aversion May Increase Inequality." Economic Journal 117:192-204.

Morelli, Massimo. 1999. "Demand Competition and Policy Compromise in Legislative Bargaining.” American Political Science Review 93:809-20.

Muthoo, Abhinay, and Kenneth A. Shepsle. 2014. "Seniority and Incumbency in Legislatures." Economics and Politics 26 (1): 13-37.

Norman, Peter. 2002. "Legislative Bargaining and Coalition Formation." Journal of Economic Theory 102 (2): 322-53.

Nunnari, Salvatore. 2012. "Dynamic Legislative Bargaining with Veto Power." Unpublished manuscript.

Nunnari, Salvatore, and Jan Zápal. 2013. "Dynamic Policy Competition, Ideological Polarization and the Value of Veto Rights." EPSA conference working paper.

Okada, Akira. 2011. "Coalitional Bargaining Games with Random Proposers: Theory and Application." Games and Economic Behavior 73 (1): 227-35.

Penn, E. Maggie. 2009. “A Model of Farsighted Voting.” American Journal of Political Science 53 (1): 36-54.

Romer, Thomas, and Howard Rosenthal. 1978. "Political Resource Allocation, Controlled Agendas, and the Status Quo." Public Choice 33:27-43.

Serra, Gilles. 2010. “A Model of Elections with Electoral Valence.” Journal of Politics 72 (2): 426-37.

Snyder, James M., Michael M. Ting, and Stephen Ansolabehere. 2005. "Legislative Bargaining under Weighted Voting." American Economic Review 95 (4): 981-1004.

Stone, Walter J., and Elizabeth N. Simas. 2010. "Candidate Valence and Ideological Positions in U.S. House Elections.” American Journal of Political Science 54:371-88.

Yildirim, Huseyin. 2007. "Proposal Power and Majority Rule in Multilateral Bargaining with Costly Recognition." Journal of Economic Theory 136:167-96.

Yildirim, Huseyin. 2010. "Distribution of Surplus in Sequential Bargaining with Endogenous Recognition.” Public Choice 142:41-57. 